\title{
Preferences heterogeneity of health care utilization of community residents in China: a stated preference discrete choice experiment
}

Ming-zhu Jiang ${ }^{1}$, Qiang Fu' ${ }^{2}$, Ju-yang Xiong ${ }^{1 *}$, Xiang-lin $\mathrm{Li}^{1}$, Er-ping Jia ${ }^{1}$, Ying-ying Peng ${ }^{1}$ and Xiao Shen ${ }^{1}$

\begin{abstract}
Background: To tackle the issue with the low usage of primary healthcare service in China, it is essential to align resource distribution with the preferences of the community residents. There are few academic researches for describing residents' perceived characteristics of healthcare services in China. This study aims to investigate the preferences of healthcare services utilization in community residents and explore the heterogeneity. The findings will be useful for the policy makers to take targeted measures to tailor the provision of healthcare services.

Methods: The face-to-face interviews and surveys were conducted to elicit four key attributes (care provider; mode of services; cost; travel time) of the preference from community residents for healthcare utilization. A rational test was presented first to confirm the consistency, and then 16 pairs of choice tasks with 12 sociodemographic items were given to the respondents. Two hypothetical options for each set, without an opt-out option, were presented in each choice task. The latent class analysis (LCA) was used to analyse the data.

Results: Two thousand one hundred sixty respondents from 36 communities in 6 cities were recruited for our study. 2019 (93.47\%) respondents completed valid discrete choice experiment (DCE) questionnaires. The LCA results suggested that four groups of similar preferences were identified. The first group (27.29\%) labelled as "Comprehensive consideration" had an even preference of all four attributes. The second group (37.79\%) labelled as "Price-driven" preferred low-price healthcare services. The third group labelled as "Near distance" showed a clear preference for seeking healthcare services nearby. The fourth group (34.18\%) labelled as "Quality seeker" preferred the healthcare service provided by experts. Willingness to pay (WTP) results showed that people were willing to accept CNY202.12(\$29.37) for Traditional Chinese Medicine (TCM) services and willing to pay CNY604.31 (\$87.81) for the service provided by experts.

Conclusions: Our study qualitatively measures the distinct preferences for healthcare utilization in community residents in China. The results suggest that the care provider, mode of senvices, travel time and cost should be considered in priority setting decisions. The study, however, reveals substantial disagreement in opinion of TCM between different population subgroups.
\end{abstract}

Keywords: Discrete choice experiment, Preference heterogeneity, Healthcare utilization

\footnotetext{
* Correspondence: xiongjuyang@hust.edu.cn

${ }^{1}$ School of Medicine and Health Management, Tongji Medical College,

Huazhong University of Science and Technology, Wuhan 430030, Hubei,

China

Full list of author information is available at the end of the article
}

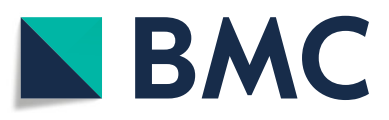

(- The Author(s). 2020 Open Access This article is licensed under a Creative Commons Attribution 4.0 International License, which permits use, sharing, adaptation, distribution and reproduction in any medium or format, as long as you give appropriate credit to the original author(s) and the source, provide a link to the Creative Commons licence, and indicate if changes were made. The images or other third party material in this article are included in the article's Creative Commons licence, unless indicated otherwise in a credit line to the material. If material is not included in the article's Creative Commons licence and your intended use is not permitted by statutory regulation or exceeds the permitted use, you will need to obtain permission directly from the copyright holder. To view a copy of this licence, visit http://creativecommons.org/licenses/by/4.0/ The Creative Commons Public Domain Dedication waiver (http://creativecommons.org/publicdomain/zero/1.0/) applies to the data made available in this article, unless otherwise stated in a credit line to the data. 


\section{Background}

China has committed itself to promoting health system reform since 2009 and this is a large-scale, long-term endeavour. The ratio of total expenditure on health to gross domestic product (GDP) increased from 5.03\% in 2009 to $6.36 \%$ in 2017 . In the same period, the government's expenditure on health increased by CNY10-15 billion (\$14.55-21.83 billion) per year [1].

Indeed, government subsidies to primary healthcare facilities (including community health centers and stations at community and district levels in urban area, county and township health centers and village clinics at county, township, and village levels in rural areas) have increased substantially: from 2009 to 2017, subsidies as a proportion of total primary healthcare facilities revenue increased from 12.3 to $32.5 \%$ [1].

However, despite the increase in funding, the proportion of outpatient visits at primary healthcare facilities decreased relative to that at tertiary hospitals, and the proportion of hospitalisations at tertiary hospitals increased. From 2012 to 2016, the proportion of outpatient services provided by hospitals among all outpatient services continued to increase by $5.1 \%$ (from 30.8 to $35.9 \%$ ). Public hospital admissions grew by $11.5 \%$ (from 61.7 to $73.1 \%$ ), while the proportion of services provided by primary healthcare facilities decreased by $7 \%$ during the same period [2], suggesting that primary care providers were not effective gatekeepers.

There might be multiple causes leading to the current low usage of primary healthcare services, including historic and institutional factors [3]. First, compared with tertiary hospitals, the supply capacity of primary healthcare facilities is insufficient. Approximately 58\% of resources were concentrated at tertiary hospitals, while only $18 \%$ at primary healthcare facilities [4]. Such resource allocation is inefficient, costly, and cannot fully meet the residents' healthcare needs [5]. Secondly, subpar medical quality and diagnostic inaccuracies exist in primary care facilities. A study revealed that only 38 and $28 \%$ of correct treatments in township health centres and village clinics were provided for patients with incognito tuberculosis, respectively [6]. A national survey showed that primary care facilities in China prescribed $52.9 \%$ of their patients with antibiotics, whereas only $39.4 \%$ of the cases required such treatment [7]. The services provided in primary healthcare facilities in China are often considered inappropriate or of poor quality, and residents tend to seek more specialised consultations and higher quality services in tertiary hospitals in lieu of primary healthcare institutions [8].

China has reached a consensus that a good primary care system is essential for the overall wellbeing of the population. Compared to the current hospital-centred and fragmented delivery system, a shift to the primary- care-centred and integrated delivery system is more effective in response to the challenges of urbanization, industrialization, population ageing, and noncommunicable chronic disease [9].

However, many supporting policies have not shown a significant effect on improving the utilization of healthcare services in primary health facilities $[10,11]$. Moreover, medical expenses have increased more rapidly since 2009. In tertiary hospitals, the outpatient fee per time increased by $15.5 \%$ from 2005 to 2008 and $21.7 \%$ from 2010 to 2013 [1]. Residents would prefer to spend more time, money and energy in tertiary hospitals rather than primary healthcare facilities for health, such healthcare seeking behaviour is deemed as costly and ineffective and hinders enhancement of service efficiency and improvements on user experience [8].

Understanding resident's preference can bridge the information gap between the healthcare demander and the health policy decision-maker [12]. A series of factors are reported to influence health services utilization [13]. The impacts of these factors are not necessarily homogenous, but may be conditional on individual and contextual factors [14]. Further scientific evidence focused on how factors affect residents' healthcare utilization is essential to encourage the usage of primary healthcare facilities in China.

Furthermore, understanding individual participation and treatment preferences can greatly improve shared decision making and their adherence. The success to measure residents' preference may conducive to the medical system reform progress and resolve the needless expenditure [15]. Once considerations of healthcare values and priorities are clearly determined, then health policy decision-makers can establish a better quality of health care system more effectively [16].

Growing evidence suggests that people make active usage choices in seeking care and highlights the need to understand resident's preference for choosing health services $[17,18]$. Many countries aim to apply residents' choices to support health service design. In UK, The London Patient Choice Project (LPCP) is established to improve choices for patients who are clinically eligible for treatment and who have been waiting for treatment at a National Health Service London hospital beyond some target waiting time. As the target waiting time approaches, patients are given an opportunity to choose from a range of alternative providers who have the capacity to offer health services in a timely manner [19].

Chinese scholars have identified the factors that could affect health care utilization. Shanshan $\mathrm{Xu}$ found that securing health insurance could increase the preference for in-patient service [20]. Xiaoqing Gan suggested that adjusting medical care reimbursement rates might contribute to meeting patients' needs [21]. Min Wei reported that factors such as operation level, nursing 
quality and equipment conditions could affect residents' choice [22]. Thus, it can be seen that there were few academic researches for describing residents' perceived characteristics of healthcare services, which hence brings a crucial need to explore preferences in depth. Residents' preferences are insufficiently included in China's policy development process, and the key to reshaping China's health care systems is to understand residents' preferences. Taking the public's demand for care as the basis of medical policy will help to enhance the value of medical services and promote rational allocation of health resources at the primary-care level.

As a non-market resource value evaluation technique, the DCE is an effective method to investigate the preference [23, 24]. DCE is grounded in Lancaster's Economic Theory of Value [25] and McFadden's Random Utility Theory [26]. In DCE's design, an individual is asked to choose between different alternatives, which are described by attributes and levels [27]. Choices are then analysed to deconstruct respondents' preferences based on the alternatives that they have chosen. When the cost is included as an attribute, marginal utility estimated from the DCE model can be converted into the willingness to pay for changes in the levels of other attributes [28]. The method of DCE has been widely used to evaluate different healthcare interventions around the world $[29,30]$. Within the context of the health care system in China, our specific aims are to explore heterogeneity in community residents' preferences for healthcare utilization and offer recommendations to promote service improvements and countermeasures. The findings will be useful in the distribution of healthcare resources and informing decision-makers on how to tailor the provision of healthcare services.

\section{Methods}

\section{Selection of choice attributes and levels for the DCE}

The performance of DCE is well described in the literature, and the literature provides clear guidance on how a DCE study should be done [31, 32]. A standard DCE consists of five steps: (1) selecting the attributes and levels to be included in the experiment, (2) developing the questionnaire and actual choice tasks presented to respondents, (3) producing a pre-test, (4) collecting data and (5) analysing the discrete choice data.

Identifying relevant preference attributes and levels is the key to design any stated-preference study [33]. People take various issues into account when deciding where they would choose to receive healthcare services. The chosen attributes and levels should be realistic and credible to respondents, so we considered two complementary stages to determine the attributes: literature review and expert consultation.

Evidence from previous research provides insights into public responses to choices, the literature review suggests the following list of ten attributes as most useful to be included: the established reputation, the opening hours [34], the follow-up arrangements [35], the type of insurance [36], the accessible of information [37], the shared decision making [38], the location of first appointment [39], the travel distance [40], the care provider [41]. Considering China's context, the mode of services was included as a specific attribute.

We conducted expert consultations in December 2017 in Wuhan, China, aiming to understand the population's current views on which factors are the most influential when choosing the healthcare service. Attributes from the literature review were collected to produce one manageable and comprehensive list for experts to rank, and ten experts (four scholars in health management and policy, three medical experts, three primary-level medical practitioners) were invited. Each participant was asked to individually rank the ten attributes in order of one (most important) to ten (least important) using a ranking sheet. Individual rankings were transferred into an Excel sheet for analysis. The included attributes should rank within the top five by $\geqslant 60 \%$ of the experts. Whilst the literature is inconclusive with regard to the number of attributes that should be included in DCE, a review shows that most studies include 4-6 attributes [42]. Based on ranking results, we chose four attributes that are most relevant to policymaking, including (1) care provider;(2) mode of services; (3) cost;(4) travel time. The care provider is the professional staff who are responsible for providing diagnosis and treatment for resident's healthcare demand including general practitioner (GP) and expert. The mode of services is the way of diagnosis and treatment including Traditional Chinese medicine (TCM), western medicine (WM) and integrated TCM and WM. The travel time refers to the time from home to healthcare institutions by the most convenient transportation way including $\leq 30$ mins and $>30$ mins.

The next step was to refine the terminology that described the attributes and their levels. The attributes were designed at 2 or 3 levels each, capturing a realistic range within China's healthcare system. For example, based on the 2017 China Statistical Yearbook, the cost ranged from CNY100 to 300 ( $\$ 14$ to 43 ). We presented all choices to our convenience sample in three formats (pictures, written description, and oral explanation). We found that a combination of written description and oral explanation was more reliable because this form would help respondents understand clearly. Table 1 presents the final attributes and levels used in our DCE.

\section{Questionnaire design}

The combination of attributes and levels resulted in 36 possible scenarios (two attributes at two levels and two attributes at three levels $=2^{2 *} 3^{2}$ ). This was a heavy burden on respondents that could adversely affect response 
Table 1 Attributes and levels used in the DCE

\begin{tabular}{|c|c|c|}
\hline Attribute & Definition & Level \\
\hline \multirow[t]{2}{*}{ Care provider } & \multirow{2}{*}{$\begin{array}{l}\text { The professional staff who is responsible for providing diagnosis and treatment for resident's } \\
\text { healthcare demand }\end{array}$} & 1.Expert \\
\hline & & 2.General practitioner (GP) \\
\hline \multirow[t]{3}{*}{$\begin{array}{l}\text { Mode of } \\
\text { services }\end{array}$} & \multirow[t]{3}{*}{ The way of diagnosis and treatment } & $\begin{array}{l}\text { 1.Traditional Chinese medicine } \\
\text { (TCM) }\end{array}$ \\
\hline & & 2.Western medicine (WM) \\
\hline & & 3.Integrated TCM and WM \\
\hline \multirow[t]{3}{*}{ Cost } & \multirow[t]{3}{*}{ Amount of money paid by patient (CNY) } & 1.CNY100 (\$14) per time \\
\hline & & 2.CNY200 (\$29) per time \\
\hline & & 3.CNY 300 (\$44) per time \\
\hline \multirow[t]{2}{*}{ Travel time } & \multirow[t]{2}{*}{ Time from home to health institutions by the most convenient transportation way } & 1. $<=30$ mins \\
\hline & & 2. $>30$ mins \\
\hline
\end{tabular}

rates. An orthogonal design using SPSS software (version 22.0) was conducted to reduce the number of choice scenarios to a practical number of 16 representative combinations, which were further divided into two blocks to reduce the burden of respondents. The two versions of questionnaires were randomly allocated to respondents. The two scenarios consisting of the four attributes were labelled as Screening Option 1 and Screening Option 2, respectively (A sample scenario is shown in Table 2). We did not leave respondents an opt-out option. This is consistent with our experiment setting: the respondents are assumed to receive medical service and must choose the service content. Moreover, an optout only introduces slight differences into the estimations, [43] whereas the forced-choice method leads to more thoughtful responses and better-quality data [44].

In addition to the DCE choices, the survey collected information on respondent's socio-demographic characteristics (e.g. sex, age, marital status, education, occupation and household size, personal monthly income) and current health situation (health insurance coverage, number of diagnosed chronic diseases). The above information was used to assess the representativeness of respondents, as well as to use as predictive factors of class membership for the analysis.

The questionnaire itself was structured as follows. First, the background of the survey was briefly introduced, followed by the 12 demographic questions. Subsequently, a warm-up question was provided to the respondents that explained the layout of the questionnaire, and then we provided people with a rationality test. Given that the respondents had an a priori tendency toward attribute level ordering, we made one of the choice alternatives clearly superior. Participants who did not choose the dominant alternative were considered to fail the test [45] and were excluded from this study. Finally, pairwise DCE choice tasks were shown. All the questionnaire information can be seen in Additional files 1 and 2 .

\section{Pilot testing}

To check the respondents' completion rates and the understanding of the questionnaire, a pilot study was undertaken among 60 voluntary residents in a community in Wuhan, China. Respondents needed $16.3 \mathrm{~min}$ on average to complete the questionnaire. We made minor changes to the layout, and our questionnaire was thought to be appropriate in length and understood easily by respondents through the pilot study.

\section{Data collection}

To make the sample representative, we selected six cities in the eastern, central and western region of China, namely, Pudong New Area, Taizhou, Wuhan, Xuchang, Chengdu and Guiyang. In each city, we selected 1 urban district and 1 suburban district randomly. In each district, we selected 3 primary care facilities according to economic level. In total, 36 primary care facilities were chosen.

Table 2 Example of a choice scenario

\begin{tabular}{lll}
\hline Attributes & Screening Option 1 & Screening Option 2 \\
\hline Mode of services & Integrated TCM and WM & TCM \\
Cost & 100 CNY & 200 CNY \\
Time travelled to medical institution & $\leq 30$ min & $>30$ min \\
Care provider & Expert & GP \\
Which one would you prefer? & $\square$ & $\square$ \\
\hline
\end{tabular}


We followed the rule of thumb proposed by Pearmain [46] that sample sizes over 100 are able to provide a basis for modelling preference data in DCE design, therefore we selected a sufficient sample size of 60 participants from each facility. A stratified sampling method was used to ensure the sample representativeness. Specifically, the strata were predefined by gender (female or male) and age (18-45 years or $>$ 45 years) of the local population [47].

After deciding the sampling sites and sample size, we cooperated with the 6 local government departments. The survey was supported by the local health bureau, and the research results would be provided to the bureau. Then the local health bureau notified the directors of primary healthcare facilities to assist in our survey preparation and organization. The directors of the sampled healthcare facilities were very cooperative and well prepared, they first screened the residential registration databases to find eligible respondents according to the given strata of gender and age, and the eligible respondents were permanent residents lived in the district including non-registered residents living in this area for more than half a year. Then the respondents were contacted to participate in the subsequent survey through phone or door-to-door visits, until the pre-defined sample quota was reached.

A formal survey was conducted in facilities. Each sampled primary healthcare facility organized a free physical examination for the respondents. After finishing the examination, the respondents took part in a face-to-face interview conducted by our trained interviewers, and paper-based questionnaires were used to ensure access and a good response rate. Informed consent of respondents was required before conducting the survey, and all of the respondents' information remained anonymous.

The interviewer specified the context and the objective of the study, the meaning of the attributes and their levels and presented an example of a choice set. During the survey, the interviewer observed the respondents' behaviour. If the choice was made based on a single attribute only [48], the respondent will be regarded as ineligible. When the surveys were finished, gifts (approximately 7.5 US dollars) were rewarded for the respondents. The inclusion criteria required the respondents who are over 18 years old, have had utilized medical services previously, could understand Chinese and independently complete the questionnaire. All documents involved in conducting the study were approved by the Ethics Committee of Tongji Medical College. This cross-sectional study was conducted from April to August 2018. In total, 2160 questionnaires were collected, and 2019 respondents passed the rationality test.

\section{Statistical analyses}

The choice data are analysed within a random utility maximization framework [49]. The most common analysis method is the use of mixed logit model to quantify the relative importance of each attribute and another one is the latent class analysis (LCA).

Considering that the population is heterogeneous in its health status owing to the variability in how health dimensions manifest over time [50] and that the DCE also contains multiple dimensions, our approach embraces this heterogeneity and complexity. Response data were analysed using the LCA, where consideration is given to both the importance of the four DCE attributes for the different classes, as well as determinants of class membership, socio-demographic factors used to predict membership were: sex (measured as female and male), age and education (in years), whether they had basic medical insurance and were under the hypothetical scenario (minor or severe chronic diseases). In this paper, the selection of the optimal number of classes was guided by the Akaike Information Criterion (AIC), the Bayesian Information Criterion (BIC), the LMR (LoMendell-Rubin) test, and the entropy. All models were specified and estimated in R-3.4.4. software.

\section{Results \\ Description of sample}

A total of 2019 valid respondents participated in this study, including 659 men and 1360 women; $47.69 \%$ of respondents were within the 18-44 age group. More than $70 \%$ of respondents received more than 9-years education and the majority of respondents were married and employed. $92.11 \%$ of respondents were covered by basic medical insurance. Self-reported results indicated that 71.93\% had no chronic diseases. The mean monthly income was CNY $4415.31(4415.31 \pm 465.34)$ or $(\$ 641.79 \pm$ 67.59). Table 3 illustrates the profile of the sample.

\section{Patterns of similar value of health care utilization attributes}

Table 4 displays the results of fitting indices of competing latent class models (two to five classes). As the number of classifications increased, both AIC and BIC initially increased and then decreased. When classification was 4, these two indicators were the lowest and the value of entropy was highest. Meanwhile, the LMR test that compared the three-class versus the four-class model achieved a significant level $(P<0.01)$. In addition, the LMR test that compared the four-class versus the five-class model did not achieve a significant level $(P>0.05)$, suggesting that the four-class model was the best one.

The results of the optimal model with four classes are given in Table 5: the upper part shows the regression coefficients for the four attributes of each class and the lower part shows the association of each class with demographic variables. 
Table 3 The characteristics of 2019 respondents

\begin{tabular}{|c|c|c|c|c|}
\hline & $\begin{array}{l}\text { Full } \\
\text { sample }\end{array}$ & $\begin{array}{l}\text { Analysis sample: Who passed the rationality } \\
\text { test }\end{array}$ & $\begin{array}{l}\text { Excluded sample: Who failed the rationality } \\
\text { test }\end{array}$ & $\begin{array}{l}X^{2}(P- \\
\text { value })\end{array}$ \\
\hline & $n=2160$ & $n=2019$ & $n=141$ & \\
\hline Variables & n (\%) & n (\%) & n (\%) & \\
\hline Sex & & & & \\
\hline Male & 734(33.98) & 659(32.63) & 75(53.19) & $2.37(.158$ \\
\hline Female & $1426(66.02)$ & $1360(67.37)$ & $66(46.81)$ & \\
\hline Age (years) & & & & $1.65(.343)$ \\
\hline $18-44$ & $981(45.41)$ & $963(47.69)$ & 18(12.76) & \\
\hline $45-59$ & $495(22.92)$ & $448(22.18)$ & 47(33.33) & \\
\hline$\geq 60$ & $684(31.67)$ & $608(30.13)$ & $76(53.91)$ & \\
\hline Marital status & & & & $2.11(.145)$ \\
\hline Married & 1767(81.81) & $1700(84.20)$ & $67(47.52)$ & \\
\hline Unmarried & $260(12.03)$ & $211(10.45)$ & 49(34.75) & \\
\hline $\begin{array}{l}\text { Divorced/Separated/ } \\
\text { Widowed }\end{array}$ & 133(6.16) & $108(5.35)$ & $25(17.73)$ & \\
\hline Length of education (years) & & & & $4.98(.274)$ \\
\hline$<9$ & $496(22.96)$ & 432(21.39) & $64(45.39)$ & \\
\hline $9-15$ & $908(42.03)$ & $884(43.78)$ & $24(17.02)$ & \\
\hline$>15$ & $756(35.01)$ & $703(34.83)$ & $53(37.59)$ & \\
\hline Monthly income (CNY) & & & & $1.67(.312$ \\
\hline$\leq 3499$ & 1003(46.43) & $961(47.59)$ & $42(29.78)$ & \\
\hline $3500-6000$ & $720(33.33)$ & 669(33.13) & $51(36.17)$ & \\
\hline$>6000$ & $437(20.24)$ & $389(19.28)$ & 48(34.05) & \\
\hline Employment & & & & $1.35(.659$ \\
\hline Employed/working & $1109(51.34)$ & $1071(53.04)$ & $38(26.96)$ & \\
\hline Unemployed & $535(24.76)$ & $471(23.32)$ & $64(45.39)$ & \\
\hline Retired & $516(23.90)$ & $477(23.64)$ & $39(27.65)$ & \\
\hline Health insurance & & & & $0.83(.846$ \\
\hline Insured & $1971(91.25)$ & 1857(92.11) & $114(80.85)$ & \\
\hline Uninsured & 189(8.75) & 162(7.89) & 27(19.15) & \\
\hline Chronic conditions & & & & $0.76(.753)$ \\
\hline Yes & $651(30.14)$ & $566(28.07)$ & $85(60.28)$ & \\
\hline No & 1509(69.86) & 1453(71.93) & $56(39.72)$ & \\
\hline Age $(\bar{x} \pm s$, years $)$ & $47.50 \pm 18.11$ & & & \\
\hline Monthly income $(\bar{x} \pm s, C N Y)$ & $4415.31 \pm 46$ & & & \\
\hline
\end{tabular}

A label is assigned to each profile based on comparisons of attribute probabilities, which are shown as follows:

The first class $(n=551,27.29 \%)$ was characterised by high probabilities of choosing all four attributes, indicating that this group had an even preference for each attribute and could obtain utility from the improvement of medical services. We labelled this group of people as "Comprehensive consideration".

The second class was the largest group $(n=763$, $37.79 \%$ ) and named as "Price-driven", with relatively high probabilities of choosing low prices, because only the coefficient of cost was significantly negative. Compared with the other three groups, the coefficient of medical expenses had a significantly higher level, indicating that this group valued price more highly than other attributes.

The third class $(n=15,0.74 \%)$ was labelled as "Near distance": only the attribute of travel time was statistically negative significant, the coefficients of attributes and demographic factor jointly showed the profile of the respondents. They were younger people under the assumption in severe chronic disease and had a clear 
Table 4 Model fit information for competing latent class model

\begin{tabular}{llllll}
\hline Number of classes & Log $(\mathrm{L})$ & AIC & BIC & entropy & LMR \\
\hline 2 & $-19,913$ & $39,877.72$ & $40,095.68$ & 0.363 & 0.241 \\
3 & $-19,824$ & $41,049.00$ & $41,434.62$ & 0.389 & 0.461 \\
4 & $-19,657$ & $39,445.25$ & $39,999.03$ & 0.433 & $<0.01$ \\
5 & $-19,621$ & $39,440.75$ & $40,156.19$ & 0.402 & 0.453 \\
\hline
\end{tabular}

preference for near distance. This group was small but had a clear preference for seeking healthcare services nearby, suggesting that distance influence the preferences of some people, but not on a large scale.

In the last group $(n=690,34.18 \%)$, individuals had the highest probabilities of choosing experts, the utility coefficient of the care provider was positive and the absolute values were significantly higher than those of the other three attributes. The coefficient of the attributes of distance and medical expenses were smaller numerically than others. Therefore, we labelled this group "Quality seeker".

The influence of demographic factors showed that individuals with lower education and younger ages had a high probability to enter group 2, people who were males, older, insured and assumed to have severe chronic diseases were more likely to enter group 4, but younger people who assumed to have severe chronic diseases were more likely to enter group 2 .

\section{Measuring willingness to pay}

WTP represents the mean maximum monetary equivalent of improvement in a single attribute and level [51], we can compute the ratio between the coefficient for each attribute and the price coefficient [52] to calculate the WTP. The results are shown in Table 6.

The average WTP showed that respondents' value of different attributes in healthcare usage from high to low was: care provider, travel time, mode of services. The quality seekers were willing to pay more for better service instead of settling for other factors, which supports the notion that this group prioritizes medical service quality.

The positive $(+)$ /negative $(-)$ results indicate theoretically to what extent the respondents would be willing to pay for or be compensated for an attribute level. The individuals were willing to pay $\mathrm{CNY} 604.31(\$ 87.84)$ to be treated by experts. A subsidy of CNY 202.12(\$29.37) was required for respondents to accept more TCM services.

\section{Discussion}

To the best of our knowledge, this is the first study to use the latent class analysis to identify a typology of preferences for health care usage across multiple dimensions in China. The LCA reveals four distinct patterns in health care choices and characteristics. Respondents can

Table 5 Results of parameter estimation of LCA

\begin{tabular}{|c|c|c|c|c|c|c|c|c|c|c|c|c|}
\hline \multirow[t]{2}{*}{ Preference } & \multicolumn{3}{|l|}{ Group 1} & \multicolumn{3}{|l|}{ Group 2} & \multicolumn{3}{|l|}{ Group 3} & \multicolumn{3}{|l|}{ Group 4} \\
\hline & Coefficient & SE. & Z-value & Coefficient & SE. & Z-value & Coefficient & SE & $Z$ value & Coefficient & SE & Z-value \\
\hline \multicolumn{13}{|l|}{ Utility function } \\
\hline $\mathrm{TCM}^{\mathrm{a}}$ & $-0.4977^{* * *}$ & 0.0735 & -6.7624 & -0.4064 & 1.1446 & -0.3551 & 5.3396 & 5.2419 & 1.0181 & $-0.5935^{* * *}$ & 0.0574 & -10.3316 \\
\hline$W M^{b}$ & -0.0148 & 0.059 & -0.2506 & 1.6497 & 1.1291 & 1.4612 & 3.9783 & 2.7063 & 1.4700 & -0.0326 & 0.0531 & -0.6136 \\
\hline Cost & $0.0034^{* * *}$ & 0.0009 & 3.4823 & $-0.0809^{* * *}$ & 0.0163 & -4.9428 & 0.0359 & 0.0350 & 1.0277 & -0.0008 & 0.0005 & -1.6432 \\
\hline Travel time ${ }^{c}$ & $-0.611^{* * *}$ & 0.0675 & -9.0253 & 0.1395 & 0.2421 & 0.5765 & $-8.5006^{*}$ & 4.0320 & -2.1083 & $0.4658^{* * *}$ & 0.0495 & 9.4014 \\
\hline Provider $^{d}$ & $-0.3681^{* * *}$ & 0.0956 & -3.8476 & 0.1035 & 0.4129 & 0.2507 & -1.8776 & 1.3905 & -1.3503 & $1.4272^{* * *}$ & 0.0755 & 18.8857 \\
\hline \multicolumn{13}{|l|}{ Influence factors } \\
\hline Sex & & & & -0.0531 & 0.0824 & -0.6432 & -0.3077 & 0.2814 & -1.0934 & $-0.0463^{*}$ & 0.1843 & -2.5165 \\
\hline Age & & & & $-0.0078^{*}$ & 0.0039 & -2.0104 & $-0.0625^{* * *}$ & 0.0131 & -4.7918 & $0.0051^{* * *}$ & 0.0089 & -5.6311 \\
\hline Education $^{f}$ & & & & $-0.2644^{* * *}$ & 0.0667 & -3.9647 & -0.2986 & 0.2035 & -1.4672 & -0.1666 & 0.1397 & -1.1932 \\
\hline Insurance ${ }^{g}$ & & & & 0.1496 & 0.1377 & 1.0862 & 4.8480 & 4.8685 & 0.9958 & $0.9840^{* * *}$ & 0.2904 & 3.3877 \\
\hline Severity $^{h}$ & & & & $0.6134^{*}$ & 0.2713 & 2.3266 & $3.1523^{* * *}$ & 0.4931 & 6.3928 & $4.3671^{* * *}$ & 0.4465 & 9.7792 \\
\hline Class share & $\mathrm{N}$ & $\%$ & & $\mathrm{~N}$ & $\%$ & & $\mathrm{~N}$ & $\%$ & & N & $\%$ & \\
\hline Predicted membership & 551 & 27.29 & & 763 & 37.79 & & 15 & 0.74 & & 690 & 34.18 & \\
\hline
\end{tabular}

Note: In this section, only the significant values are highlighted in bold. The cost and age are continuity variables

${ }^{*} p<0.05 ;{ }^{* *} p<0.01 ;{ }^{* * *} p<0.001$

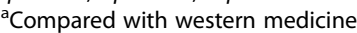

${ }^{\mathrm{b}}$ Compared with integrated TCM and WM

${ }^{c}$ Compared with less than or equal to $30 \mathrm{mins}$

${ }^{\mathrm{d}}$ Compared with GP

ecompared with male

${ }^{f}$ Compared with shorter length of education( $\leq 9$ years)

${ }^{9}$ Compared without basic medical insurance

${ }^{\mathrm{h}}$ Compared with the assumption that have minor chronic disease 
Table 6 Results of WTP for each attribute

\begin{tabular}{llllll}
\hline Level & Gourp1 & Group2 & Group3 & Group4 & Average (95\% Cl) \\
\hline Mode of services & 144.68 & -5.02 & -148.36 & 697.78 & $-202.12(-204.43$ to -201.34$)$ \\
Cost & 4.32 & 20.37 & 110.58 & -38.34 & $+4.90(4.63$ to 7.36$)$ \\
Travel time to medical institution & 177.51 & 1.73 & 236.29 & 547.62 & $+238.01(222.48$ to 244.83) \\
Care provider & 107.04 & 1.28 & 52.19 & 1677.85 & $+604.31(591.76$ to 610.45) \\
\hline
\end{tabular}

be divided into four groups: comprehensive consideration, price-driven, near distance and quality seeker. Different factors drive people to make their choice of healthcare usage, revealing preference heterogeneity.

The results of group 1 indicate that healthcare policy will need to be multidimensional. The preferences of respondents for multiple dimensions of health care usage suggests that the policy focus solely on strengthening medical capabilities might not be acceptable. Indeed, all respondents place value on travel time, suggesting that medical care accessibility and availability are important. We also find that the proportion of group 2 and 4 is high. From this perspective, they are more likely to be influenced by a broader influence of the allocation of healthcare resources.

Furthermore, respondents in group 2 would prefer primary healthcare services at lower prices, which is in line with the pursuit of maximizing utility. Moreover, in China, one of the government's goals for developing the primary health care system is to provide residents with services that are relatively inexpensive and convenient. According to the results of our study, the goal of this policy is consistent with the residents' preferences.

Interestingly, choosing to visit a large-size hospital or medical expert has been the level the respondents in group 4 preferred most for care, regardless of traveling distance. Many residents in China still go to hospitals for both minor and serious illnesses [53]. One of the most important reasons is that residents seek healthcare unrestrictedly. A notion has been held in Chinese is that a higher level of health institutions provides better quality care. The past imbalanced allocation of health resources has intensified residents' distrust of primary healthcare facilities. Hence, the tiered medical system would not be successful if residents' opinions are ignored. To address this complicated problem, it is necessary to guide residents to seek medical treatment based on their perceived value for service quality [54] and carry out comprehensive health-centred services in primary healthcare facilities.

A unique result is that the respondents of group 3 have a clear and significant preference for near distance. Travelling distance to healthcare facilities will affect patients' medical decision-making by considering time and transportation cost. It is more likely that due to the increase in the degree of information asymmetry, patients will appear irrational behaviours of "loss avoidance" preferences in uncertain environments [55]. The presence of distance decay effects in healthcare services has been demonstrated by most studies [56]. A review shows that the further a patient lives from the healthcare facilities they need to attend, the worse their health outcomes are [57]. These suggest that distance/travel time should be a consideration when configuring the health resources. China is trying to establish a 15-min circle of healthcare services by the year 2030 and residents can walk within 15 min to the most convenient medical centers around their home. The convenience of healthcare service has been emphasized and by combining such factors as distance, accessibility will ensure the equity of healthcare services.

Our large-scale study also provides new information about demographic characteristics and health status that could have a significant impact on healthcare preferences. Men, the elderly, the insured, and those who assumed to have severe chronic diseases will pay more attention to service quality. People with lower education and younger age would pay more attention to the price of medical services. We can find that the quality and price of healthcare service are the core of basic healthcare and the cornerstone of the desired medical and health service system. With an ageing population and an increase in chronic diseases and comorbidities, health services should concentrate on the health of the population and devote attention to the community residents to prevent disease, decrease prevalence or delay its onset [58]. Previous studies have shown that low-income people are not only in a disadvantaged position in wealth, but also in health [59]. Therefore, we should consider subsidising medical care for low-income people to improve their health. On the other hand, we can strengthen prevention by expanding health promotion and education to reduce the likelihood of illness.

There are great differences among respondents who are willing to pay for healthcare services. Results show that people have the highest level of the willingness to pay for expert services, reflecting that the public values medical service quality. On the other hand, our research finds that a subsidy of CNY 202.12(\$29.37) is important for respondents to accept more TCM services. It indicates that the level of compensation should be in line with public preferences to improve the benefit and accessibility of primary health services. The TCM is profound, has its own unique advantages and can be conducive to provide better personalized and targeted 
primary healthcare services. The vigorous development of traditional medicine services is inseparable from policy support, which can achieve the goal of optimising medical resource allocation and harmonising the diversity of healthcare demand. It is necessary to formulate the supporting policy such as increasing human resources and technical support, which will bring TCM's superiority into full play in primary healthcare facilities [60].

Health service usage is a complex behaviour affected by many factors, and the preferences of individuals may change as a function of one's health status [61]. More research is needed to examine these groups in different contexts. One is interactions between attributes and their effects on preference for healthcare usage. Given the complex and multifaceted nature of health, it may be that preferences for one attribute are influenced by preferences for another. Another is to examine factors that lead these groups to map future transition of service use, deep qualitative studies about quality of life over time or large cohort studies need to be conducted. This would help policymakers and healthcare providers align with public's preferences. There are more women than men in our study, part of it is that gender imbalanced structure in older people has become a noticeable issue in China's population distribution, and the statistical yearbook data in 2019 shows that there are more elderly women than men, with a sex ratio of less than 100 [62]. The other part is due to the hollowed-out of population structure in rural and suburban areas, the massive of young and middle-aged labour force flow outward, resulting in that most of the population in rural and suburb areas are elderly, women $[63,64]$. In the actual survey, women were also more attracted by our incentives and they were more proactive and enthusiastic in taking part our study in the workday.

\section{Limitations}

Several study limitations should be noted. First, the LCA can identify the preference heterogeneity, but are unable to discover the underlying behavior reason in depth, and can be better explained through qualitative interviews [65]. Second, since a maximum number of five attributes is suggested, we selected the most important attributes for the study. There may be some other factors that are missed. Third, respondents need to make choices under certain circumstances, and the stated preference may be different from the revealed preference. We used WTP merely as an estimate of the relative utility of services and not as an indication of true WTP [66]. Fourth, the probable cause for unbalanced gender structure has been explained above and this reminds us to deal with the balance between representativeness of sample and research feasibility.

\section{Conclusions}

Among people using healthcare services, we find that their behaviour could be described in four groups: overall consideration, price-driven, near distance and quality seeker. The results suggest that the care provider, mode of services, travel time and cost should be considered in priority setting decisions. The study also reveals substantial disagreement in the opinion of Traditional Chinese Medicine between different population subgroups. Effectively measuring the preference of healthcare delivery from the perspective of the demander is essential to increase service efficiency within resource constraints. The policy should be multidimensional, not only emphasis strengthening the accessibility and availability of healthcare services, but also guide the residents to seek healthcare services properly and rationally. Moreover, the policy should consider improving the socio-economic status of the population to improve their health outcome.

\section{Supplementary information}

Supplementary information accompanies this paper at https://doi.org/10. 1186/s12913-020-05134-4.

Additional file 1. *Questionnaire: Version 1.

Additional file 2. * Questionnaire: Version 2.

\section{Abbreviations}

LCA: Latent class analysis; DCE: Discrete choice experiment; WTP: Willingness to pay; TCM: Traditional Chinese Medicine; GDP: Gross domestic product; LPCP: The London Patient Choice Project; GP: General practitioner; WM: Western medicine; AIC: Akaike information criterion; BIC: Bayesian information criterion; LMR: Lo-Mendell-Rubin test

\section{Acknowledgements}

We would like to thank the local heath bureaus and the primary healthcare facilities for assisting in the recruitment of the participants. We would like to thank our respondents in China for their willingness to participate. We would also thank Shunping Li, Shimeng Liu, Eden Zhu, John Chen for assisting in polishing and proofreading the manuscript.

\section{Authors' contributions}

MZJ completed the data collection and analyses, and wrote the manuscript. Q. F guided the critically revised the manuscript. JY. X conceptualized the study and edited the manuscript. XL. L collected the data and edited the manuscript. EP. J and YY. P participated data collection and analysis. X. S participated data collection and study design. All authors have read and approved the final manuscript.

\section{Funding}

This work was supported by the National Natural Science Foundation of China (NO.71673095). The funders had no role in study design, data collection and analysis, decision to publish or preparation of the manuscript.

\section{Availability of data and materials}

The datasets used and analyzed during the current study are available from the corresponding author on reasonable request. Contact information: xiongjuyang@hust.edu.cn.

\section{Ethics approval and consent to participate}

All the respondents provided informed oral consent before conducting the survey. In the study, all respondents joined voluntarily and were informed that no identifiable personal data would be collected. The respondents answered the questionnaire anonymously, so we did not require written consent. Ethical approval (No: IORG0003571) was obtained for the consent 
procedure and for the study as a whole from the Ethics Committee of Tongji Medical College, Huazhong University of Science and Technology, and the research adhered to the tenets of the Declaration of Helsinki.

\section{Consent for publication}

Not applicable.

\section{Competing interests}

The authors declare there are no competing interests.

\section{Author details}

'School of Medicine and Health Management, Tongji Medical College, Huazhong University of Science and Technology, Wuhan 430030, Hubei, China. ${ }^{2}$ Department of Epidemiology and Biostatistics, College for Public Health and Social Justice, Saint Louis University, St. Louis, MO, USA.

Received: 11 August 2019 Accepted: 20 March 2020

Published online: 18 May 2020

\section{References}

1. National Health and Family Planning Commission. China's health statistics yearbook 2018. Beijing: Peking Union Medical College Press; 2018.

2. National Health and Family Planning Commission. China's health and family planning statistics yearbook in 2017. Beijing: Peking Union Medical College Press; 2017.

3. Wu D, Lam TP. Underuse of primary Care in China: the scale, causes, and solutions. The J Am Board Family Med. 2016;29(2):240-7. https://doi.org/10. 3122/jabfm.2016.02.150159.

4. Yip W, Fu HQ, et al. 10 years of health-care reform in China: progress and gaps in universal Health coverage. Lancet. 2019;394(10204):1192-204. https://doi.org/10.1016/S0140-6736(19)32136-1.

5. World Bank Group, W.H.O., Ministry of Finance, National Health and Family Planning Commission, Ministry of Human Resources and Social Security. Deepening health reform in China: building high-quality and value-based service delivery. 2016.

6. Sylvia S, Xue H, Zhou C, et al. Tuberculosis detection and the challenges of integrated care in rural China: a cross-sectional standardized patient study. PLoS Med. 2017;14(10):e1002405. https://doi.org/10.1371/journal.pmed.1002405.

7. Wang J, Wang P, Wang X, Zheng Y, Xiao Y. Use and prescription of antibiotics in primary health care settings in China. JAMA Intern Med. 2014; 174(12):1914-20. https://doi.org/10.1001/jamainternmed.2014.5214.

8. Lin F, Sun Q, Peng Z, Cai J, et al. The innovations in China's primary health care reform: development and characteristics of the community health services in Hangzhou. Family Med Commun Health. 2015;3(3):52-66. https:// doi.org/10.15212/FMCH.2015.0135.

9. Yip W, Hsiao W. Harnessing the privatization of China's fragmented healthcare delivery. Lancet. 2014;384(9945):805-18. https://doi.org/10.1016/S01406736(14)61120-X.

10. National Health Commission of the People's Republic of China, 2019. National medical service utilization from January to November in 2019. http://www.nhc.gov.cn/mohwsbwstjxxzx/s7967/202001/55e9bcc9829e412 78ea29d15e2ad10c1.shtml. Accessed 23 Feb 2020

11. Qingyue M, Mills A, Longde W, Qide H. What can we learn from China's health system. BMJ. 2019;365:12349. https://doi.org/10.1136/bmj.I2349.

12. Fields BE, Bell JF, Bigbee JL, Thurston H, Spetz J. Registered nurses' preferences for rural and urban jobs: a discrete choice experiment. Int J Nurs Stud. 2018;86:11-9. https://doi.org/10.1016/j.jinurstu.2018.05.012.

13. Olenja J. Health seeking behaviour in context. East Afr Med J. 2003;80(2):616. https://doi.org/10.4314/eamj.v80i2.8689.

14. Andersen RM, Davidson PL. Improving access to care in America: individual and contextual indicators. In: Changing the US Health Care System: Key Issues in Health Services Policy and Management; 2007. p. 3-31.

15. Craig BM, Mitchell SA. Examining the value of menopausal symptom relief among US women. Value Health. 2016;19(2):158-66. https://doi.org/10.1016/ j.jval.2015.11.002

16. Victoor A, Delnoij DM, Friele RD, et al. Determinants of patient choice of healthcare providers: a scoping review. BMC Health Serv Res. 2012;12(1):272. https://doi.org/10.1186/14726963-12-272.

17. Scott KW, Jha AK. Putting quality on the global health agenda. N Engl J Med. 2014;371(1):3-5. https://doi.org/10.1056/NEJMp1402157.
18. Kruk ME, Nigenda G, Knaul FM. Redesigning primary care to tackle the global epidemic of noncommunicable disease. Am J Public Health. 2015; 105(3):431-7. https://doi.org/10.2105/AJPH.2014.302392.

19. Burge P, Devlin N, Appleby J, Rohr C, Grant J. London Patient Choice Project Evaluation: A model of patients' choices of hospital from stated and revealed preference choice data. RAND Corporation; 2005.

20. Xu S, Gao Q, Nini B, Li S. Analysis of the consumption preferences of patients join in the new rural cooperative medical system from the perspective of game theory. Chinese Health Economics. 2013;32(3):50-1.

21. Gan X, You M, Hu K. Reimbursement gap, patient behavior and medical expenses a three-stage dynamic game analyses. Systems EngineeringTheory \& Practice. 2014;34(11):2974-83.

22. Wei M, Xiao J. Study on influencing factors and countermeasures analyses of choosing a different medical institutions by patients. Chinese Health Management. 2014:4:259-61.

23. Albada A, Triemstra M. Patients' priorities for ambulatory hospital care centres: a survey and discrete choice experiment among elderly and chronically ill patients of a Dutch hospital. Health Expect. 2009;12(1):92-105. https://doi.org/10.1111/j.1369-7625.2009.00533.x.

24. Bujosa A, Riera A, Hicks RL. Combining discrete and continuous representations of preference heterogeneity: a latent class approach. Environ Res Econ. 2010;47(4):477-93. https://doi.org/10.1007/s10640-010-9389-y.

25. Lancaster K. A new approach to consumer theory. J Polit Econ. 1966;72(2): 132-57. https://doi.org/10.1086/259131.

26. McFadden D. The choice theory approach to market research. Mark Sci. 1986;5(4):275-97. https://doi.org/10.1287/mksc.5.4.275.

27. Adamowicz W, Boxall P, Williams M, Louviere J. Stated preference approaches for measuring passive use values: choice experiments and contingent valuation. Am J Agric Econ. 1998;80(1):64-75. https://doi.org/10.2307/3180269.

28. Bien DR, Danner M, Vennedey V, Civello D, Evers SM, Hiligsmann M. Patients' preferences for outcome, process and cost attributes in Cancer treatment: a systematic review of discrete choice. Patient Centered Outcomes Res. 2017; 10(5):553-65. https://doi.org/10.1007/s40271-017-0235-y.

29. Vass C, Gray E, Payne K. Discrete choice experiments of pharmacy services: a systematic review. Int J Clin Pharm. 2016;38(3):620-30. https://doi.org/10. 1007/s11096-015-0221-1.

30. Quaife M, Terris-Prestholt F, Di Tanna GL, Vickerman P. How well do discrete choice experiments predict health choices? A systematic review and metaanalysis of external validity. Eur J Health Econ. 2018;19(8):1053-66 https:// doi.org/10.1007/s10198-018-0954-6.

31. Coast J, Al-Janabi H, Sutton EJ, Horrocks SA, Vosper AJ, Swancutt DR, et al. Using qualitative methods for attribute development for discrete choice experiments: issues and recommendations. Health Econ. 2012;21(6):730-41 https://doi.org/10.1002/hec.1739.

32. Flynn D, Ternent L, Becker F, Oluboyede Y, Adams J. Parental preferences for the Organization of Preschool Vaccination Programs Including Financial Incentives: a discrete choice experiment. MDM Policy Pract. 2017;2(1):1-13. https://doi.org/10.1177/2381468317708319.

33. Ryan M, Mclntosh E, Dean T, Old P. Trade-offs between location and waiting times in the provision of health care: the case of elective surgery on the Isle of Wight. J Public Health Med. 2000;22(2):202-10. https:/doi.org/10.1093/pubmed/22.2.202

34. Ahmed A, Fincham JE. Physician office vs retail clinic: patient preferences in care seeking for minor illnesses. Ann Fam Med. 2010;8(2):117-23. https://doi. org/10.1370/afm.1052.

35. Van den Berg B, Van Dommelen P, Stam P, Laske-Aldershof T, Buchmueller T, Schut FT. Preferences and choices for care and health insurance. Soc SCi Med. 2008;66(12):2448-59. https://doi.org/10.1016/j.socscimed.2008.02.021.

36. Thomson S, Dixon A. Choices in health care: the European experience. J Health Serv Res Policy. 2006;11(3):167-71. https://doi.org/10.1258/ 135581906777641703.

37. Baxter K, Glendinning C, Clarke S. Making informed choices in social care: the importance of accessible information. Health Soc Care Commun. 2008; 16(2):197-207. https://doi.org/10.1111/j.1365-2524.2007.00742.x.

38. Ryan M, Farrar S. Using conjoint analysis to elicit preferences for health care. Br Med J. 2000;320(748):1530-3. https://doi.org/10.1136/bmj.320.7248.1530.

39. Tinelli M, Nikoloski Z, Kumpunen S. Decision-making criteria among European patients: exploring patient preferences for primary care services. Eur J Pub Health. 2014;25(1):3-9. https://doi.org/10.1093/eurpub/cku082.

40. Muehlbacher AC, Johnson FR. Choice experiments to quantify preferences for health and healthcare: state of the practice. Appl Health Econ Health Policy. 2016;14(3):253-66. https://doi.org/10.1007/s40258-016-0232-7. 
41. Gerard K, Salisbury C, Street D, et al. Is fast access to general practice all that should matter? A discrete choice experiment of patients' preferences. Health Serv Res Policy. 2008;13(Suppl 2):3-10. https://doi.org/10.1258/jhsrp. 2007.007087.

42. Kleij KS, Tangermann U, Amelung VE, et al. Patients' preferences for primary health care- a systematic literature review of discrete choice experiments. BMC Health Serv Res. 2017;17(1):476. https://doi.org/10.1186/s12913-017-2433-7.

43. Fiebig D, Louviere JJ, Waldman D. Contemporary Issues in Modelling Discrete Choice Experimental Data in Health Economics. Working paper. Australia: University of New South Wales; 2005.

44. Veldwijk J, Lambooij MS, de Bekker-Grob EW, et al. The effect of including an opt-out option in discrete choice experiments. PLoS One. 2014;9(11): e111805. https://doi.org/10.1371/journal.pone.0111805.

45. Lancsar E, Donaldson C. Discrete choice experiments in health economics: distinguishing between the method and its application. Eur J health Econ. 2005;6(4):314-6. https://doi.org/10.1007/s10198-005-0304-3.

46. Pearmain D, Swanson J, Kroes E, Bradley M. Stated preference techniques: a guide to practice. 2nd ed. London: Steer Davies Gleave and Hague Consulting Group; 1990.

47. National Bureau of Statistics of China, 2010. The 2010 Population Census.

48. Tervonen T, Schmidt-Ott T, Marsh K, Bridges JFP, Quaife M, Janssen E. Assessing rationality in discrete choice experiments in health: an investigation into the use of dominance tests. Value Health. 2018;21(10): 1192-7. https://doi.org/10.1016/j.jval.2018.04.1822.

49. McFadden D. Conditional logit analysis of qualitative choice behaviour. In: Frontiers in Econometrics, Zarembka, editiors. New York: Academic Press; 1974. p. 105-42.

50. Lafortune L, Beland F, Bergman H, Ankri J. Health status transitions in community-living elderly with complex care needs: a latent class approach. BMC Geriatr. 2009;9(1):6-20. https://doi.org/10.1186/1471-2318-9-6.

51. Homburg C, Koschate N, Hoyer WD. Do satisfied customers really pay more? A study of the relationship between customer satisfaction and willingness to pay. J Mark. 2005;69(2):84-96. https://doi.org/10.1509/jmkg.69.2.84.60760.

52. Milte R, Ratcliffe J, Chen G, Crotty M. What characteristics of nursing homes are most valued by consumers? A discrete choice experiment with residents and family members. Value Health. 2018;21(7):843-9. https://doi. org/10.1016/j.jval.2017.11.004.

53. Tang C, Luo Z, Fang P, Zhang F. Do patients choose community health services (CHS) for first treatment in China? Results from a community health survey in urban areas. J Community Health. 2013;38(5):864-72. https://doi. org/10.1007/s10900-013-9691-z.

54. Wu J, Zhang S, Chen $\mathrm{H}$, et al. Patient satisfaction with community Health service centers as gatekeepers and the influencing factors: a cross-sectional study in Shenzhen, China. Plos One. 2016;11(8):e0161683. https://doi.org/10. 1371/journal.pone.0161683.

55. Cui Zhen J, Chuanyong L, Guohua Z. Optimal medical distance, medical fairness and irrational medical behavior. Jiangxi Soc Sci. 2019;39(5):73-84.

56. Mcgrail M, Humphreys J. Measuring spatial accessibility to primary care in rural areas: Improving the effectiveness of the two-step floating catchment area method. Appl Geography. 2009;29(4):533-41. https:/doi.org/10.1016/j.apgeog.2008.12.003.

57. Kelly C, Hulme C, Farragher $T$, et al. Are differences in travel time or distance to healthcare for adults in global north countries associated with an impact on health outcomes? A systematic review. BMJ Open. 2016;6:e13059. https://doi.org/10.1136/bmjopen-2016-013059.

58. Kuang $L$. Approach for defining and conceptualizing the core attributes of general practice. Chinese J Health Policy. 2017;10(5):1-6.

59. Muurinen JM. Demand for health: a generalised Grossman model. J Health Econ. 1982;1(1):5-28 https://doi.org/10.1016/0167-6296(82)90019-4.

60. Su Y, Guo DD, Wei W, Yu HY, Zhang L, Xiong JY. Give full play to the advantages of traditional Chinese medicine to promote the implementation of hierarchical medical system under the new Health system reform. Chinese Hospital Management. 2016;36(3):4.

61. Lagarde M, Erens B, Mays N. Determinants of the choice of GP practice registration in England: evidence from a discrete choice experiment. Health Policy. 2015;119(4):427-36. https://doi.org/10.1016/j.healthpol.2014.10.008.

62. National Health Commission of the People's Republic of China, 2019. China statistical yearbook in 2019.http://www.stats.gov.cn/tjsj/ndsj/2019/indexch. htm. Accessed 23 Feb 2020.

63. Smith G. The Hollow State: Rural Governance in China. The China Quarterly. 2010;203:601-18. https://doi.org/10.1017/S0305741010000615.
64. Ye J. Stayers in China's "hollowed-out" villages: A counter narrative on massive rural-urban migration. Population, Space Place. 2017:e2128. https:// doi.org/10.1002/psp.2128.

65. Liu Y, Kong Q, de Bekker-Grob EW. Public preferences for healthcare facilities in rural China: A discrete choice experiment. Soc Sci Med. 2019;237: 112396. https://doi.org/10.1016/j.socscimed.2019.112396.

66. Nieboer AP, Koolman X, Stolk EA. Preferences for long-term care services: willingness to pay estimates derived from a discrete choice experiment. Soc Sci Med. 2010;70(9):1317-25. https://doi.org/10.1016/j.socscimed.2009.12. 027..

\section{Publisher's Note}

Springer Nature remains neutral with regard to jurisdictional claims in published maps and institutional affiliations.
Ready to submit your research? Choose BMC and benefit from:

- fast, convenient online submission

- thorough peer review by experienced researchers in your field

- rapid publication on acceptance

- support for research data, including large and complex data types

- gold Open Access which fosters wider collaboration and increased citations

- maximum visibility for your research: over $100 \mathrm{M}$ website views per year

At BMC, research is always in progress.

Learn more biomedcentral.com/submissions 